\title{
O jornalismo nos conglomerados globais: prestação de serviços e entretenimento ${ }^{1}$
}

\author{
Virginia Pradelina da Silveira Fonseca ${ }^{2}$ \\ Universidade Federal do Rio Grande do Sul \\ virginia@ufrgs.br
}

\begin{abstract}
Resumo: $O$ artigo faz uma reflexão sobre as implicações da racionalidade pós-fordista, e da introdução das novas tecnologias de comunicação e informação, no jornalismo produzido no âmbito das indústrias culturais contemporâneas. Para isso, primeiramente, faz-se uma breve discussão sobre a estrutura social emergente no início do século XXI. A seguir, discorre-se sobre as variadas concepções de jornalismo ao longo da história da imprensa brasileira, e sua relação com as distintas etapas do capitalismo. Por fim, levanta-se a hipótese de que, sob o regime de acumulação flexível em vigor, em algumas empresas multimídia e em vias de transnacionalização, uma nova tendência possa estar a se estruturar: a prevalência do entretenimento e da prestação de serviços em detrimento da notícia de interesse público. A perspectiva de análise é a da Economia Política da Comunicação.
\end{abstract}

Abstract: This is a reflective article about the implications of post-fordism rationality and the introduction of information/communication new technologies in Journalism as it is produced by contemporary cultural industry. To do so, I started with a brief discussion of the emergency of new social structures in the beggining of this XXI century. And, after that, taking a look on the various concepts of journalism in Brazilian press history, as related to the distinctive stages of capitalism, constructing the hypothesis that, under a flexible accumulative regime some multimidia enterprise, even in transnationazation process, could be working on a new way of structuring itself directed to an overwhelming tendency for "entertainement and services" instead of news and public interest predominancy. The main

\footnotetext{
${ }_{1}^{1}$ Parte deste trabalho foi apresentado como comunicação no VI Lusocom, realizado em Covilhã, Portugal, de 21 a 24 de abril de 2004.

2 Jornalista, doutora em Comunicação e Informação, professora adjunta na Faculdade de Biblioteconomia e Comunicação da Universidade Federal do Rio Grande do Sul.
} 
perspective of the article is that one of Communication Political Economy.

Résumé: L'article fait une reflexion sur les implications de la rationalité post-fordienne, e de l'introdution des nouvelles tecnologies de comunication et d'information, dans le journalisme produit au sein des industries cultureles contemporaines. Pour cela, tout d'abord, on fait une lègere discussion sur la structure sociale emergeant au début du XXI siècle. Tout de suite, on realize une rapide discussion sur les diferéntes conceptions de journalisme, et leur raport avec les diferéntes étapes du capitalisme. Finalement, on lève l'hipothèse que, sous le régime d'acumulation flexible existant, dans quelques entreprises multimedia et en voie de transnationalisation, une nouvelle tendence puisse être en train de se structurer: le domaine de l'entreteniment et de prestation de services en prejudice des notices d'interéret public. La perspective d'analyse est celle de l'economie politique de communication.

Resumo: El artículo hace una reflexión sobre las implicaciones de la racionalidad posfordismo, y de la introducción de las nuevas tecnologías de comunicación y información en el periodismo producido en el ámbito de las industrias culturales contemporáneas. Para eso, primeramente, se hace una breve discusión sobre la estructura social emergente en el inicio del siglo XXI. A seguir, se discurre sobre las variadas concepciones de periodismo a lo largo de la historia de la prensa brasileña, y su relación con las distintas etapas del capitalismo. Por fin, se levanta la hipótesis de que, bajo el régimen de acumulación flexible en vigor, en algunas empresas multimidia y en vías de transnacionalización, una nueva tendencia pueda estar estructurándose: el prevalecimiento del entretenimiento y de la prestación de servicios en detrimento de la noticia de interés público. La perspectiva de análisis es la de la economía política de la comunicación.

Palavras-chave: jornalismo - economia política - pósfordismo

Key-words: Journalism - Communication Political Economy - Post-Fordism

Les mots-clé: Journalisme - Economie Politique de Communication - Post-fordienne.

Palabras llave: periodismo - economía política posfordimo 


\section{Introdução}

Este artigo visa a uma reflexão quanto às implicações da introdução das novas tecnologias de comunicação e informação e da lógica do regime de acumulação pós-fordista nas indústrias culturais contemporâneas, particularmente no jornalismo como atividade social. Para isso, primeiramente, faz-se uma breve discussão sobre a estrutura social emergente no início do século XXI, para, a seguir, discorrer-se sobre as variadas concepções de jornalismo vigentes ao longo da história da imprensa brasileira. Por fim, levanta-se a hipótese de que, sob o regime de acumulação flexível em vigor, uma nova tendência começa a tomar forma.

A perspectiva geral de análise é a da Economia Política da Comunicação.

\section{Estrutura social emergente}

A transição do século XX para o século XXI ocorre marcada por transformações tão profundas na estrutura das sociedades capitalistas ocidentais que nos é permitido considerar a hipótese, pelo menos, de que estamos diante de um tipo de revolução. São transformações de natureza econômica, social, política e cultural, que atingem a todos - indivíduos, sociedades, nações, estados, organizações - e todos os contextos sociais, embora com diferentes impactos.

A idéia de revolução aqui utilizada não tem o sentido clássico de ruptura. A história nos tem demonstrado que os processos de mudança ocorrem muito mais por acúmulos, por continuidades, que por rupturas. Tem o sentido gradualista proposto por Gould (1980), ao dizer que a história da vida é uma série de situações estáveis, pontuadas em intervalos raros por eventos importantes que ocorrem com grande rapidez e ajudam a estabelecer a próxima era estável.

A profundidade das transformações que vêm ocorrendo desde o final do século passado, mais precisamente a partir da década de 1990, permite a Castells (2000), por exemplo, sustentar a hipótese de revolução com base no 
conceito de Gould. Ao constatar a emergência de uma nova estrutura social uma "sociedade em rede" -, o sociólogo do planejamento urbano e regional da Universidade da Califórnia, Berkeley, diz que o momento atual constitui um desses raros intervalos na história. Este teria começado a se configurar a partir do desenvolvimento das novas tecnologias de comunicação e informação, nos anos 1970, e da reestruturação mundial do capitalismo, nos anos 1980. Esses eventos, articulados, é que estariam a sustentar as mudanças atuais, nos mais diversos âmbitos da vida, e dando origem ao que denomina de sociedade em rede - global, capitalista e informacional.

Entretanto, mesmo que não tomada no sentido clássico de ruptura, a idéia de revolução como representação das transformações em curso é controversa. Autores oriundos de outras matrizes de pensamento negam seu caráter revolucionário. Garnham ${ }^{3}$ (2003) argumenta que tais transformações não configuram revolução, mas mudanças lentas, que vão ocorrendo por camadas, sobrepondo-se, em contextos em que coexistem situações antigas e novas, estas minando aquelas e vice-versa. Harvey (2001), também de tradição teórica distinta de Castells ${ }^{4}$, ao discorrer sobre modernidade e pósmodernidade na cultura, dedica parte considerável de seus estudos sobre as origens da mudança cultural a investigar as transformações políticoeconômicas do capitalismo do final do século XX.

O autor não se detém na questão específica das novas tecnologias, mas sustenta a existência de algum tipo de relação entre a ascensão de formas culturais pós-modernas, a emergência de modos mais flexíveis de acumulação do capital e um novo ciclo de "compressão do tempo-espaço" na organização do capitalismo. Assim, sustenta a hipótese da emergência de um novo regime de acumulação - o de Acumulação Flexível, ou Pós-Fordista5. Para Harvey

\footnotetext{
3 Nicholas Garnham é teórico da vertente inglesa da Economia Política da Comunicação. 4 David Harvey é um dos principais representantes da Escola Francesa de Regulação, outra vertente da Economia Política de extração marxista, enquanto Manuel Castells é weberiano. 5 Regime de acumulação integrante da etapa monopólica do capitalismo que se opõe à rigidez do fordismo. Apóia-se na flexibilidade dos processos de trabalho, dos mercados de trabalho, dos produtos e dos padrões de consumo. Caracteriza-se também pela progressiva
} 
(2001), o novo regime começa a se estruturar no início da década de 1970, quando se instala o processo que leva à substituição do regime de acumulação Fordista, em vigor nos países capitalistas avançados desde o final da Segunda Guerra Mundial.

Mesmo que não estejam de acordo quanto à idéia de revolução, e que o termo tenha significados diferentes para weberianos e neomarxistas, o fato é que a maioria dos analistas sociais contemporâneos reconhece a existência e a profundidade das mudanças que marcam o final do século XX e os primórdios do século XXI.

Em razão disso, é-se levado a inferir que estamos de fato nos defrontando com a construção de um novo paradigma de organização social, independentemente da denominação que receba, ou dos critérios utilizados para sua nomeação e análise. O período histórico que começa a se configurar nas últimas décadas do século XX pode ser chamado de sociedade em rede ou capitalismo informacional (Manuel Castells), pós-industrialismo (Daniel Bell), pós-fordismo (David Harvey), pós-modernismo (Fredric Jameson), capitalismo tardio (Ernest Mandel), ou mesmo pode indicar o fim da história (Francis Fukuyama). O que parece inegável é que se trata da emergência de um novo modelo, que se estrutura em torno das tecnologias de informação e comunicação e de um capitalismo renovado e mundial.

Ao discorrer sobre as teorias do pós-moderno, Jameson (1996) observa que elas mantêm grande semelhança com todas as generalizações sociológicas mais ambiciosas que, mais ou menos na mesma época, anunciam novidades quanto à chegada, ou à inauguração, de um novo tipo de sociedade, cujo nome mais famoso seria "sociedade pós-industrial", proposto por Daniel Bell. O autor lembra que essa nova sociedade também pode ser conhecida por sociedade da informação, sociedade das mídias, sociedade eletrônica ou hightech, entre outras denominações. Tais teorias, segundo ele, teriam a missão

desregulamentação, pelo surgimento de setores de produção inteiramente novos, por novas maneiras de fornecer serviços financeiros, por novos mercados e por taxas altamente intensificadas de inovação comercial, tecnológica e organizacional (Harvey, 2001, p. 140). 
ideológica de demonstrar que a nova formação social não mais obedeceria às leis do capitalismo clássico, isto é, o primado da produção industrial e a luta de classes. Por isso, encontrariam resistência veemente dos pensadores de tradição marxista. A exceção entre estes seria o economista Ernest Mandel, para que a nova formação social - que denomina de capitalismo tardio - nada mais é que um estágio do capitalismo, o mais puro em relação a qualquer dos momentos que o precederam (Jameson, 1996).

Sem pretender encontrar consensos para o que é, por natureza, controverso, o que se quer ressaltar é que as transformações em curso estão a determinar a próxima era estável em todas as formas de manifestação da vida humana, da economia à política, da organização do Estado à cultura. Atingem pessoas, empresas, instituições, estados, movimentos sociais, organizações de todo gênero. E podem ser tomadas como indícios de uma revolução, desde que a entendamos como aumento repentino e inesperado de aplicações tecnológicas que transformam processos de produção e distribuição, criam novos produtos e mudam decisivamente a localização das riquezas e do poder no mundo (Castells, 2000).

\section{O desenvolvimento do capital e as concepções de jornalismo no Brasil}

Historicamente, o jornalismo é uma prática social que constitui um dos elementos de formação da opinião pública. Organizada de modo capitalista, a mídia jornalística é parte da esfera pública onde se formata esse fenômeno de difícil definição chamado opinião pública (Rüdiger, 2003). Apesar da imprecisão conceitual, em tempos regidos pela afirmação de idéias relativas à visibilidade e à transparência, a opinião pública constitui um fator de referência a orientar a ação de governos, empresas, movimentos sociais, partidos políticos, organizações não-governamentais, etc.

Dos ideais do Iluminismo e da Revolução Francesa, o jornalismo herda o papel de intérprete dos fatos/eventos/fenômenos da atualidade considerados relevantes pela opinião pública. O conceito que regula essa prática social, no 
entanto, foi se modificando ao longo do tempo, condicionando e sofrendo os condicionamentos dos períodos históricos e contextos singulares em que é exercido. As Quatro Teorias da Imprensa ${ }^{6}$, formuladas por Siebert, Schramm e Peterson, em 1956, permitem-nos compreender essas mudanças, na medida em que constituem "enfoque normativo sobre a forma de funcionamento dos meios de comunicação de massa nos diferentes tipos de sociedade" (Kunczik, 1997, p. 74).

No Brasil, conheceu-se a imprensa tardiamente em relação a outros países, inclusive latino-americanos7. Foi só no século XIX, quando a família real portuguesa transferiu-se para a colônia, em 1808, que tivemos a impressão e a circulação dos dois primeiros periódicos: o Correio Braziliense, feito em Londres por Hipólito José da Costa, e a Gazeta do Rio de Janeiro, publicação oficial produzida na Imprensa Régia, sob rígido controle da Coroa.

O conceito de jornalismo, contudo, não se define no momento em que se implanta a imprensa no Brasil. Rüdiger (2003) nos alerta para a possibilidade de haver imprensa sem que haja o correspondente jornalismo. Argumenta que pode haver imprensa literária, sindical, religiosa, humorística, sem que estas possibilitem o exercício do jornalismo. A advertência é feita em razão da necessidade de distinguir entre conceitos que facilmente podem ser confundidos. O autor designa jornalismo a prática social componente do processo de formação da opinião pública que, dotada de conceito histórico variável conforme o período, pode estruturar-se de modo regular nos mais diversos meios de comunicação, de jornais à televisão. Compartilhando essa idéia, Genro filho (1989) completa dizendo que a imprensa nada mais é que o corpo material do jornalismo, sua base tecnológica, indispensável para a divulgação de informações, capaz de multiplicar e transportar conteúdos

\footnotetext{
${ }^{6}$ As Quatro Teorias da Imprensa formuladas por Sieber, Schramm e Peterson são: a teoria autoritária, surgida da filosofia estatal do absolutismo, no século XVI; a teoria liberal, que teve seu auge no século XIX; a teoria da responsabilidade social e a teoria comunista soviética (Kunczik, 1997, p. 74-79).

7 O México conheceu a imprensa em 1539; o Peru, em 1583; as colônias inglesas (Guiana e Trinidad \& Tobago), em 1650 (Sodré, 1983).
} 
jornalísticos em proporções de espaço e de tempo radicalmente diferentes da comunicação interpessoal direta ou dos métodos artesanais (Genro Filho, 1989).

Conforme os registros historiográficos, o conceito subjacente à prática social jornalismo no Brasil assume distintas feições ao longo do tempo, de acordo com a forma como a atividade se institucionaliza. Essa organização institucional caminha paralelamente, ou até mesmo subordinada, à estruturação e ao desenvolvimento do capitalismo no país.

No princípio, pode-se dizer até que a imprensa existente à época do Correio Braziliense e Gazeta do Rio de Janeiro, assim como no período da Independência, não tinha características lhe fossem próprias - as características não eram da imprensa, mas do período histórico. Não havia um conceito de jornalismo por trás da atividade artesanal de reproduzir textos impressos. Conforme Sodré (1983), autor dessa tese, os jornais publicados nas primeiras décadas do século XIX refletiam o ardor apaixonado do debate político travado: primeiro, em torno da questão da Independência; depois, em torno da estrutura do Estado-Nacional a ser moldada a partir da separação de Portugal. Os pasquins, que vicejaram no período da Regência ao final da primeira metade do século XIX, são exemplos disso. A linguagem panfletária, virulenta, difamatória, a periodicidade irregular e a produção artesanal, entre outras características, são próprias mais do contexto que da imprensa. Tratava-se de um tipo de jornalismo político, mas de vozes desconexas, sem uma causa a lhes unificar a ação. Tinham tais características, segundo o historiador, porque "brotavam da vida" - serviam a público pequeno, de nível baixo, usando as armas que a época oferecia e permitia - a injúria e a difamação. A educação estava em estado rudimentar, o ensino era pouco difundido, havia uma massa de analfabetos, e os que sabiam ler não compreendiam as questões públicas Eram formais e vazios, numa época em que a educação era tida como adorno. 
Não encontrando a linguagem precisa [...], a norma política adequada aos seus anseios [...], derivavam para a vala comum da injúria, da difamação, do insulto repetido. Não podiam fazer uso de outro processo porque não o conheciam, não estavam em condições de utiliza-lo (Sodré, 1983, p. 157).

O autor sustenta, entretanto, que o período Regencial (1831-1840) constitui um momento de ascensão liberal entre o Primeiro e o Segundo Reinado, quando os valores nacionais se afirmam e em que prevalecem algumas características de regime republicano, como eleições, primazia do legislativo sobre o executivo e ampla liberdade de imprensa.

O período de conciliação que se inicia com a união de conservadores e liberais em torno da figura de D. Pedro II, na primeira fase do II Império, a partir de 1840, é marcado pelo recuo da luta política e pela aproximação com a literatura. Muitos dos principais representantes do Romantismo brasileiro tornam-se conhecidos do público e se consagram como grandes escritores na labuta das oficinas onde se produziam os jornais da época. Machado de Assis, José de Alencar e Joaquim Manuel de Macedo são exemplos bastante significativos.

O conteúdo político dos jornais é retomado nas últimas décadas do século XIX, quando todas as instituições nacionais - o escravagismo, o latifúndio cafeeiro, a Igreja e o próprio regime monárquico - passam a ser questionadas. A fase que começa no final dos anos 1860 e se estende até as últimas décadas é especialmente importante porque é quando se encontra no Brasil, pela primeira vez, uma organização jornalística de natureza empresarial.

A Província de São Paulo, fundado em 1875, é o primeiro jornal brasileiro a ser organizado como empresa. O negócio é resultado da iniciativa de um grupo de comerciantes, fazendeiros, empresários e jornalistas de São Paulo. Embora seus fundadores tivessem vínculos inegáveis com o Partido Republicano, apresenta-se ao público como independente e comprometido com uma organização empresarial. O mesmo ocorre com o Jornal do Brasil, 
de 1891, no Rio de Janeiro, e com o Correio do Povo, de 1895, no Rio Grande do Sul. De forma que podemos localizar as raízes da grande imprensa brasileira fincadas no final do século XIX, embora só se consolidem no século XX.

Essa recuperação histórica sucinta justifica-se pela necessidade de se identificar um conceito de jornalismo subjacente às distintas formas de organização institucional que o jornalismo brasileiro vem experimentando desde o seu surgimento. Exceto no período em que os jornais foram lançados diretamente pelo Estado, ou por ele subsidiados, no seio do processo de estruturação do Estado-Nacional, pode-se afirmar que o desenvolvimento da imprensa jornalística no Brasil caminha no rastro do desenvolvimento do capitalismo nacional, confirmando a tese habermasiana ${ }^{8}$ a respeito do desenvolvimento da imprensa.

O esforço para se organizar como empresa foi a alternativa, primeiro de jornalistas, depois de empresários da comunicação, de libertar os jornais do controle dos grupos políticos, do aparelhamento dos periódicos por parte dos segmentos em disputa pelo poder. A Província de São Paulo (que após a proclamação da República se transforma em O Estado de São Paulo), Jornal do Brasil e Correio do Povo, para citar apenas três, são representativos desse esforço de jornal-empresa, teoricamente mais comprometidos com o interesse público, ainda que esse fosse um objetivo apenas retórico. No caso de $\mathrm{O}$ Estado de São Paulo, alguns analistas asseguram que seu discurso de independência servia para dar maior credibilidade às lutas do Partido Republicano na fase das reformas. Já o Jornal do Brasil acolhia o pensamento conservador de Rodolfo de Souza Dantas e Joaquim Nabuco, este um notório monarquista, na primeira fase do regime Republicano (Bahia, 1990). E o Correio do Povo, como bem observa Rüdiger (2003), resultou da percepção

\footnotetext{
${ }^{8}$ A tese sustenta que o desenvolvimento da imprensa decorre tanto do desenvolvimento capitalista, na medida em que a revolução comercial fomenta simultaneamente o trânsito de mercadorias e de informações, quanto da intervenção do Estado, na medida em que este patrocina direta ou indiretamente os jornais, usados para comunicação com a classe letrada (Habermas, 2003).
} 
de seu fundador, Caldas Júnior, de que o caráter político do jornalismo não precisava ser explícito. A organização empresarial, entretanto, contribui para dar viabilidade econômica às publicações e, concomitantemente, para instituir um conceito para o jornalismo.

O conceito de jornalismo como informação de atualidades passa a vigorar a partir do momento em que se desenvolve e se consolida a grande imprensa brasileira, no século XX. Até aí, a imprensa havia sido, alternadamente, literária e política. Da década de 1920 em diante vários novos títulos vão surgir (O Globo, Folha de São Paulo, revista O Cruzeiro, Revista do Globo, etc.), introduzindo o jornalismo brasileiro, de forma definitiva, na fase empresarial.

O desenvolvimento técnico e organizacional dessa imprensa das primeiras décadas do século XX, considerada por alguns como representativa dos primórdios de uma indústria cultural, vai acompanhar, contudo, os avanços e os recuos do capitalismo no cenário nacional. Quando este era de estagnação, como na República Velha, assim se reproduzia na imprensa jornalística. Nessa fase, os jornais eram graficamente feios e editorialmente desinteressados das questões políticas, mais ocupados da própria sobrevivência e menos com a formação e a direção de uma opinião pública.

À medida que o capitalismo começa a se estruturar, depois da Revolução de 1930, com o aprofundamento das reformas e a implantação de uma infraestrutura que servirá de base para a industrialização futura, esses avanços também se refletem na organização das empresas jornalísticas e na qualidade dos jornais, atingindo também o conceito da atividade jornalística.

A década de 1960 é marcada por grandes transformações. Ao ser adquirido por Otávio Frias de Oliveira e Carlos Caldeira Filho, em 1962, o grupo Folha da Manhã começa a se constituir como grande complexo de indústria cultural. Em 1966, para fazer frente à concorrência das Folhas, o grupo O Estado de São Paulo lança o vespertino Jornal da Tarde, com caráter absolutamente inovador para os padrões da época. E, no mesmo ano, a 
Editora Abril lança a revista Realidade, que se torna uma referência na grande reportagem, seguida depois por Veja, de 1968, revista semanal de informações de maior circulação no país até os dias de hoje.

Os novos títulos vêm se juntar à série de publicações que vinham das décadas anteriores, como as da rede de Diários e Emissoras Associados, de Assis Chateaubriand, e do grupo Última Hora, de Samuel Wainer. No Rio Grande do Sul, dois novos jornais são lançados na mesma década: a unidade gaúcha do Última Hora, em 1960, e Zero Hora, em 1964. A profusão de novos títulos, e as reformas gráficas, editoriais e administrativas implementadas por publicações já consolidadas, como o próprio Jornal do Brasil, no final dos anos 1950, irão caracterizar um período de modernização da imprensa jornalística. Essa modernização, marcada pelo crescente empresariamento e profissionalização, vai preparar a mídia jornalística para o ingresso na era das indústrias culturais, o que ocorre a partir da década de 1960, consolidando-se plenamente nos anos 1970.

A consolidação das empresas de comunicação do Brasil em indústrias culturais é fenômeno vinculado ao ingresso do país na fase monopólica do capitalismo internacional (Ortiz, 1991; Taschner, 1992; Lopes, 1994; LattmanWeltman, 2003), processo de "modernização" econômica coordenada pelos sucessivos governos militares pós-1964.

A fase monopólica do capitalismo brasileiro, da mesma forma que nos países de capitalismo avançado, realiza-se sob regimes de acumulação distintos. Nos anos 1970 e 1980, sob o fordismo, observa-se a plena subordinação do jornalismo à lógica capitalista.

A partir dos anos 1990, sob o pós-fordismo, tem-se um aprofundamento dessa subordinação, desse caráter mercadológico da informação, que passa a ser instrumento de lucro e de poder dos mais importantes nas sociedades contemporâneas. 


\section{O jornalismo na nova estrutura social}

Como se disse de início, o objetivo deste artigo é refletir, à luz da bibliografia, sobre as transformações no jornalismo a partir da introdução de dois novos fatores na vida das indústrias culturais contemporâneas: as novas tecnologias de comunicação e informação e a expansão em escala mundial de um novo regime de acumulação - o regime pós-fordista, ou de acumulação flexível9 (Harvey, 2001). No Brasil, esse processo que vai se acentuar dos anos 1990 em diante, com continuidade nestes primeiros anos do século XXI.

$\mathrm{Na}$ fase que melhor se delineia na década de 1990, os conglomerados de comunicação, em nível mundial, começam a enfrentar um profundo processo de reestruturação, deixando de se reportar aos mercados internos apenas para se dirigir para um mercado de âmbito global. Nessa conjuntura, começa a ganhar contorno um novo desenho na institucionalização das mídias em geral. Numa nova onda de concentração, de propriedade e de capital, os conglomerados nacionais de comunicação começam a se estruturar como conglomerados transnacionais multimídia, com foco na informação, na prestação de serviços e no entretenimento, o que provoca mudanças no jornalismo produzido no interior desse tipo de organização.

Acredita-se que as implicações dessas mudanças sobre a atividade social chamada jornalismo precisam ser analisadas num quadro teórico amplo, que permita compreender as restrições encontradas por este para cumprir seu papel histórico - o de intérprete e analista da realidade social - diante das contingências impostas por uma organização institucional subordinada às regras e à lógica das distintas etapas do desenvolvimento capitalista no Brasil.

\footnotetext{
9 Por regime de acumulação entende-se a estabilização, por um longo período, do produto líquido entre consumo e acumulação. Isso implica alguma correspondência tanto das condições de produção como das condições de reprodução de assalariados. Segundo o autor, um sistema particular de acumulação existe porque seu esquema de reprodução é coerente. (Harvey, 2001).
} 
Quais as implicações para o jornalismo da introdução da lógica do regime de acumulação pós-fordista nas indústrias da mídia? Como isso se reflete na organização das empresas, nas rotinas de produção e na concepção de jornalismo? Que competências e habilidades são exigidas dos jornalistas nesse novo ambiente?

Do ponto de vista organizacional, as empresas de comunicação ingressam na era das fusões, das associações, dos acordos operacionais. Isso dá novo impulso à concentração de propriedade (vertical, horizontal, cruzada e em cruz $^{10}$ ) e de capital. Trata-se das convergências - tecnológica e financeira. Novas empresas surgem, e podem desaparecer, da noite para o dia, como resultado da associação de capitais das mais diversas origens (nacionalidades e setores), integrando as mais variadas plataformas técnicas. Com isso, capitalizam-se para atuar no mercado mundial e compartilham riscos. No Brasil, em janeiro de 2005, um dos maiores grupos de mídia do país, a Folha de São Paulo, anunciou a criação da holding Folha-UOL, para centralizar a administração das várias empresas do grupo e, a seguir, para viabilizar sua associação à transnacional Portugal Telecom ${ }^{11}$, empresa que atua no ramo de telefonia ${ }^{12}$. Antes, em 2004, a editora Abril, havia se associado ao fundo de investimentos norte-americano Capital International, Inc $^{13}$. No mesmo ano, no setor de televisão por assinatura, Sky e Direct TV passaram ao comando da NewsCorp, organização cujo principal acionista é Rupert Murdoch.

Quanto às rotinas de produção, entre muitas outras inovações, surgem o jornalismo on line e a produção e atualização das notícias em "tempo real", um exemplo da compressão do espaço-tempo de que fala Harvey (2001),

${ }^{10}$ Classificação dos tipos de concentração de propriedade da fase atual das indústrias da mídia (Lima , 2001).

${ }^{11}$ A participação da Portugal Telecom na holding seria de 21,09\%, conforme noticiado pela imprensa à época da publicização do negócio.

${ }_{12}$ No Brasil, a empresa portuguesa atua através da operadora de telefonia móvel Vivo.

13 Essas associações de grupos nacionais de mídia a empresas de capital estrangeiro se dão sob o amparo da Emenda Constitucional $n^{0}$ 36, de 2002, regulamentada pela Lei 10.610, de dezembro de 2002. 
assim como a convergência das mídias tradicionais (rádio, tv, jornal) para a rede mundial de computadores (internet) e desta para as mídias tradicionais (Garnham, 2003). Exemplo significativo do quanto a convergência tecnológica e a estruturação das empresas em organizações multimídia alteram as rotinas produtivas na redação de um jornal, por exemplo, é o perfil múltiplas habilidades e multimídia que passa a ser requerido dos jornalistas de Zero Hora, no Rio Grande do Sul. Embora as experiências em multimídia não sejam generalizadas, limitando-se a alguns profissionais e a algumas situações, até a primeira metade de 2005, a capacidade de executar múltiplas tarefas e de assumir múltiplas competências na redação do jornal de referência do grupo RBS já é considerada um pré-requisito.

Em conseqüência, o perfil profissional que emerge dessa estrutura é o do intelectual do tipo experto ${ }^{14}$, profissional com múltiplas habilidades e competências, capacitado tecnicamente para a produção de conteúdos, nem sempre jornalísticos, com estrutura e linguagem apropriadas para veiculação em todos os suportes técnicos.

Acredita-se que tantas e tão profundas transformações refletem-se na concepção de jornalismo operada no interior dessas novas organizações. Supõe-se que, à medida que vai se tornando apenas mais um dos serviços oferecidos ao público "consumidor" por empresas multimídia e de variada composição de capital, a atividade social jornalismo também vai se afastando da sua histórica "missão" de intérprete e analista diário dos eventos-notícia de relevância e interesse público, para se aproximar de uma atividade cujo conceito se define predominantemente pela prestação de serviços, pelo entretenimento e por critérios publicitários, em detrimento de critérios jornalísticos. Esse aspecto das mudanças condicionadas pela nova etapa do capitalismo global, sob a lógica da flexibilidade reinante no novo regime de

${ }_{14}$ No sentido atribuído por Bobbio, de intelectual-técnico, que detém os conhecimento adequados para alcançar determinado fim. (Bobbio, 1997, p. 118-119). 
acumulação, permanece em aberto, a espera de melhor e mais acurada análise.

\section{Considerações finais}

Diante dessa nova conjuntura macro-estrutural, levanta-se a hipótese de que a nova concepção de jornalismo em emergência no início do século XXI, cuja denominação ainda está por ser formulada, distancia-se do conceito inaugurado pela Teoria da Responsabilidade Social, que toma o jornalismo como notícia, e esta como o relato objetivo de um evento atual de interesse público.

Independentemente das críticas que se formulem a respeito dessa concepção funcionalista do jornalismo e da notícia, e das possibilidades de se alcançar a “verdade”, esta é a concepção hegemônica até então, legitimada tanto pelo público quanto pelo campo profissional. E é esta concepção que, diante da crescente subordinação do jornalismo às novas estruturas em que é produzido, está ameaçada. A notícia, entendida como o relato, a interpretação e a análise de fato/evento de interesse público, vem perdendo o caráter de expressão do jornalismo. Em algumas dessas novas organizações multimídia, vem se definindo cada vez menos por critérios de noticiabilidade vinculados ao interesse público e mais por critérios relativos à prestação de serviços e entretenimento. A cada dia, novos cadernos, seções e produtos são lançados com a finalidade muito mais de entreter que de informar, explicar e analisar o que é, por natureza, complexo na realidade social. Assim, o jornalismo vai se desfigurando, deixando de significar forma de conhecimento para se configurar como mero serviço.

Da mesma forma, o jornalista distancia-se da condição de mediador aquele que relata, explica, interpreta e analisa questões de interesse público para a sociedade, contribuindo para o esclarecimento e a formação da opinião pública. 
A tendência que se delineia é a de um jornalismo basicamente informativo (de uma informação não necessariamente com atributos jornalísticos), prestador de serviços e/ou de entretenimento, totalmente subordinado à lógica capitalista da organização que o explora como negócio. Além disso, esse padrão serve a interesses ideológicos de classe, talvez menos explícitos, mas nem por isso menos influentes.

A concentração de propriedade e de capital (oligopólios transnacionais) leva ao controle da informação (produção, armazenagem, disponibilidade e acesso) e, conseqüentemente, ao controle do poder. A discussão desse tema não interessa apenas a jornalistas e a pesquisadores do campo da comunicação, mas a toda a sociedade, pelas implicações que tem para a democracia política e para a diversidade cultural no Brasil e no mundo. Porque, como observa Lima (1999), as sociedades contemporâneas são centradas na mídia, que tem o poder de construir a realidade, em longo prazo, por meio da representação dos diferentes aspectos da vida humana.

São sociedades que dependem da mídia - mais do que da família, da escola, das igrejas, dos sindicatos, dos partidos etc. - para a construção do conhecimento público que possibilita, a cada um dos seus membros, a tomada cotidiana de decisões. Por não se pode reduzir a importância das comunicações apenas à transmissão de informações [...]. Elas não são canais neutros. Ao contrário, são construtoras de significação. (Lima, 2001, p. 113).

Como se antecipou, a análise das implicações dessa nova forma de organização institucional no conceito de notícia, e as conseqüências do regime de acumulação em emergência no interior dessas organizações, é fundamental para se compreender a extensão e a profundidade das transformações em curso no jornalismo. O caráter recente dessas mudanças ao mesmo tempo em que pode ser um fator de limitação para a investigação criteriosa, uma vez que se trata de objeto em constante mutação, pode também ser um fator de estímulo e, quem sabe, de alguma forma de intervenção no rumo dos acontecimentos. 


\section{Bibliografia}

BAHIA, Juarez. Jornal, história e técnica. São Paulo: Ática, 1990.

BOBBIO, Norberto. Os intelectuais e o poder. São Paulo: Ed. da UNESP, 1997. CASTELLS, Manuel. A Sociedade em Rede. $4^{\mathrm{a}}$ ed. Rio de Janeiro: Paz e Terra, 2000.

GENRO FILHO, Adelmo. O segredo da Pirâmide: para uma teoria marxista do jornalismo. $2^{\mathrm{a}}$ ed. Porto Alegre: Ortiz, 1989.

GOULD, Stephen J. The Panda's Thumb: more reflections on Natural History. Nova York: W.W. Norton, 1980.

HABERMAS, Jürgen. Mudança estrutural da esfera pública: investigação quanto a uma categoria da sociedade burguesa. $2^{\mathrm{a}}$ ed. Rio de Janeiro: Tempo Brasileiro, 2003.

HARVEY, David. Condição pós-moderna: uma pesquisa sobre as origens da mudança cultural. 10 ${ }^{\mathrm{a}}$ ed. São Paulo: Loyola, 2001.

JAMESON, Fredric. Pós-modernismo: a lógica cultural do capitalismo tardio. São Paulo: Ática, 1996.

LATTMAN-WELTMAN, Fernando. Mídia e transição democrática: a (des)institucionalização do pan-óptico no Brasil. In: ABREU, Alzira Alves de; LATTMAN-WELTMAN, Fernando; KORNIS, Mônica Almeida. Mídia e política no Brasil: jornalismo e ficção. Rio de Janeiro: Ed. FGV, 2003 (129183).

LIMA, Venício A. de. Mídia: teoria e política. São Paulo: Ed. Fundação Perseu Abramo, 2001.

KUNCZIK, Michael. Conceitos de jornalismo: Norte e Sul. São Paulo: Editora da USP, 1997.

ORTIZ, Renato. A moderna tradição brasileira: cultura brasileira e indústria cultural. $3^{\text {a }}$ ed. São Paulo: Brasiliense, 1991.

RÜDIGER, Francisco. Tendências do jornalismo. $3^{\mathrm{a}}$ ed. Porto Alegre: Ed. Universidade/UFRGS, 2003.

SODRÉ, Nelson Werneck. A história da imprensa no Brasil. São Paulo: Martins Fontes, 1983.

TASCHNER, Gisela. Folhas ao vento: análise de um conglomerado jornalístico no Brasil. Rio de Janeiro: Paz e Terra, 1992.

Summus, 1987. Do jornalismo político à indústria cultural. São Paulo: 